

\title{
Gênero e o Assédio Moral nos Espaços Organizacionais de Trabalho: Exclusão que Causam Feridas
}

\author{
Género y Acoso Moral en los Espacios Organizacionales de Trabajo: \\ Exclusión que Causa Heridas
}

\section{Gender and Moral Harassment in Organizational Working Spaces: Exclusion that Causes Wounds}

Resumo

O presente artigo tem por objetivo analisar a extensão do assédio moral em relação ao gênero nos espaços organizacionais de trabalho, uma vez que as mulheres vêm conquistando cada vez mais espaços no mundo do trabalho, mas ainda continuam sendo tratadas de forma discriminatória, humilhante e muitas vezes doentia acarretando isolamento e a redução da sua autoestima. Apesar da Constituição Federal Brasileira e da legislação infraconstitucional trazerem diversos dispositivos de proteção à mulher, o assédio moral representa um dos grandes problemas trabalhistas contemporâneo, tendo em vista que as condutas machistas ou sexistas estão muitas vezes presentes no espaço laboral. Em razão da complexidade da temática "gênero e assédio moral nas organizações" associada aos espaços de trabalho, nesta pesquisa serão analisados alguns fatores e indicadores que contribuem para o assédio moral de gênero nas várias dimensões do trabalho sob a luz da Geografia que permite através de uma metodologia própria a compreensão integrada das realidades sociais. É nesta perspectiva que a questão do assédio moral ao gênero se enquadra na investigação geográfica e aponta que as diferenças físicas, biológicas e sociais entre mulheres e homens contribui para promover desigualdades e revelar que as mulheres estão mais vulneráveis e são frequentemente mais assediadas no ambiente de trabalho que os homens.

Palavras-Chave: Gênero; Trabalho; Assédio Moral; Espaço; Organizações.

\section{Resumen}

El presente artículo tiene como objetivo analizar la extensión del acoso moral en relación al género en los espacios organizacionales de trabajo, una vez que las mujeres vienen conquistando cada vez más espacios en el mundo del trabajo, más aún continúan siendo tratadas de forma discriminatoria, humillante y muchas veces ninguneada, acarreando aislamiento y la reducción de su autoestima. A pesar de la Constitución Federal Brasileña y de la legislación infra constitucional traen diversos dispositivos de protección a la mujer, el acoso moral representa uno de los mayores problemas laborales contemporáneos, teniendo en cuenta que las conductas machistas o sexistas están muchas veces presentes en el espacio laboral. En razón de la complejidad de la temática "género y acoso moral en las organizaciones" asociada a los espacios laborales; en esta investigación serán analizados algunos factores e indicadores que contribuyen para el acoso moral de género en varias dimensiones del trabajo sobre la luz de la Geografía que permite a través de una metodología propia la comprensión integrada de las realidades sociales. Es en esta perspectiva que la cuestión del acoso moral al género se encuadra en la investigación geográfica y apunta que las diferencias físicas, biológicas y sociales entre hombres y mujeres contribuyen para promover desigualdades y revela que las mujeres están más vulnerables y son frecuentemente más acosadas en el ambiente laboral que los hombres.

Palabras-Clave: Género; Trabajo; Acoso Moral; Espacio; Organizaciones. 


\begin{abstract}
The objective of this article is to analyze the extent of gender-based harassment in the workplace, as women have been gaining more and more space in the world of work, but are still treated in a discriminatory, humiliating and sometimes ill-mannered way causing isolation and reducing their self-esteem. Although the Brazilian Federal Constitution, under the infraconstitutional legislation brings various protection mechanisms to women, moral harassment represents one of the major contemporary labor problems, given that sexist behaviors are often present in the workplace. Due to the complexity of the theme "gender and harassment in organizations" associated with work spaces, this study will analyze some factors and indicators that contribute to gender harassment in the various dimensions of work under the light of Geography that based on a proper methodology allows an integrated understanding of social realities. It is from this perspective that the issue of gender-based harassment fits into geographic research and points out that physical, biological and social differences between men and women contribute to promote inequalities and reveal that women are more vulnerable and usually face more harassment in the workplace than men.
\end{abstract}

Keywords: Gender; Work; Bullying; Space; Organizations.

\title{
Introdução
}

As relações de trabalho encontram-se subordinadas ao modo de produção capitalista, fruto da exploração do trabalho que consequentemente gera as desigualdades entre gêneros. Nesse sentido a geografia não é alheia às preocupações de gênero no mundo do trabalho, sobretudo nos estudos das diferenças e desigualdades sociais entre homens e mulheres e as suas consequências na organização e utilização do espaço. Quando se pensa na igualdade de tratamento entre os gêneros nas relações de trabalho, temos que pensar na diversidade existente entre mulheres e homens, na orientação sexual e na luta pelos direitos das mulheres que implica na luta pela diversidade que se acrescenta aos fatos históricos.

Além das diferenças biológicas entre os gêneros, as piores coisas de ser mulher estão relacionadas direta ou indiretamente ao machismo tanto na esfera pública quanto na privada, com ênfase na subordinação aos homens. No mercado de trabalho, as mulheres sofrem mais com a violência e a discriminação.

A discriminação e a violência de gênero surgem como pano de fundo para o assédio moral nos espaços organizacionais de trabalho. Vale ressaltar que não há previsão legal na legislação trabalhista quanto ao assédio moral, exceto em algumas leis esparsas, tipificando a conduta do assédio moral. Entretanto, ele já é reconhecido pela doutrina e jurisprudência e tem sido objeto de estudos específicos.

A inexistência de uma legislação específica sobre o tema no âmbito da relação de emprego surge à necessidade de identificar os elementos caracterizadores para diferenciar o fenômeno assédio moral de outros fenômenos causadores de conflitos interpessoais no ambiente de trabalho.

O assédio moral, quando praticado dentro da empresa, é considerado um ato preocupante, visto que é uma ação permanente que afeta a vítima psicologicamente causando danos à sua saúde física e mental, sua vida pessoal 
e seu desempenho profissional.

Ressalta-se que não é toda e qualquer atitude que pode ser caracterizada como assédio moral, sendo assim, durante a presente pesquisa, serão relatadas algumas práticas para que haja uma melhor compreensão e diferenciação acerca do ato que envolve o assédio moral no trabalho.

\section{Procedimentos Metodológicos}

Com a finalidade de conhecer um pouco mais sobre o assédio moral, fenômeno global que tem as mulheres como suas principais vítimas nas organizações, propôs-se um estudo das relações de gênero nos espaços organizacionais de trabalho de empresas públicas e privadas, uma vez que a exposição prolongada de trabalhadoras a situações vexatórias, humilhantes ou depreciativas praticadas dentro das organizações de trabalho podem gerar consequências devastadoras e irreversíveis a vida pessoal, profissional e principalmente integridade psicológica dessas trabalhadoras.

Diante desse contexto, tomamos como estratégia de aproximação, a participação em discussões com as mulheres que trabalham em empresas publicas e privadas com o objetivo de buscar informações acerca de práticas de assédio moral que são cometidos dentro das empresas. Apesar de termos um número expressivo de mulheres que sofrem assédio moral dentro das organizações, poucas aceitam a falar sobre o assunto. Este fato permitiu dirigir a pesquisa para a compreensão e análise que comprovam que a coação moral incidente nas relações empregatícias, atinge não só princípios constitucionais, mas principalmente mulheres, haja vista que as condutas assediadoras afetam diretamente no que concerne aos direitos das trabalhadoras.

Diante de tal perspectiva, procurou-se escolher um método de estudo adequado e coerente com o problema proposto na pesquisa. Realizou-se uma abordagem qualitativa utilizando questionário padronizado aplicado em entrevistas semiestruturadas com perguntas abertas e fechadas, cujo cenário de estudo envolveu 05 empresas públicas e privadas do município de Porto Velho/RO. Para o estudo do tema, desenvolveu-se um questionário com 30 perguntas objetivas e subjetivas que abordavam sobre assédio moral de gênero nas relações de trabalho e as práticas assediadoras.

A seleção das participantes do estudo, foi por adesão espontânea, visto a análise populacional de mulheres existentes nas empresas estudadas, que incluíram área de educação, saúde pública e escritórios de advocacia. Para extrair detalhes e informações de como as práticas inoportunas e abusivas atingem em regra, a integridade física e moral das mulheres no espaço laboral, utilizou-se perguntas abertas, onde permitiu responder livremente, usando linguagem própria e emitindo opiniões sobre as atitudes e práticas assediadoras de cunho sexista.

Os questionários aplicados nas empresas previamente selecionadas foram respondidos de forma individual após agendamento com as trabalhadoras. No início de cada entrevista, o estudo foi brevemente apresentado, deixando-se claro sobre a garantia de privacidade e segurança das informações, antes de solicitar a autorização, em duas vias, do termo de consentimento livre e esclarecido. Optou-se por esta metodologia porque o assédio é uma forma de 
violência psíquica praticada no local de trabalho, por meio de condutas de perseguição repetitivas e prolongadas, onde o agressor tenta inferiorizar a vítima.

Após a aplicação do questionário que contou com a participação de 26 mulheres que trabalham em diversos ramos e atividades profissionais como: gerentes, professoras, coordenadoras, profissionais da saúde e administrativos, os dados foram submetidos à análise seguindo três etapas:

$\mathrm{Na}$ primeira etapa os dados foram organizados por meio de leituras sistematizadas dos relatos das entrevistas, partindo das questões contidas no questionário.

A segunda se deu com a exploração do material coletado a fim de alcançar a compreensão dos textos escritos.

A terceira tratou-se da interpretação dos resultados e nesse momento os pesquisadores dialogaram com a fundamentação teórica adotada, estabelecendo correlações com as informações provenientes de outros estudos.

Assim, as observações e relatos desta pesquisa perpassam por aspectos que referenciam a hostilidade provocada pela prática do assédio moral, os agravos e prejuízos causados à saúde física e mental do assediado e a exposição das trabalhadoras a situações humilhantes e constrangedoras.

\section{Espaços Organizacionais de Trabalho e Assédio Moral}

O espaço organizacional é produzido pelo trabalho de homens e mulheres de forma coletiva, onde sociedade não pode operar fora dele, uma vez que impõe sua própria realidade. Nesse sentido, o espaço organizacional de trabalho como um todo reúne todas as formas e locais de funcionalização e organização de sociedade, atuando como elemento mediador entre sociedade e a produção do espaço.

Nesse contexto, o mundo organizacional é uma sociedade de organizações constituída por espaços, onde passamos a maior parte do tempo de nossas vidas. Assim, as organizações constituem um arranjo deliberado de pessoas que cuidam de recursos no sentido de alcançar objetivos e propósitos específicos.

Nas palavras de Bollnow (2008, p. 18) “o espaço tampouco é para o homem um meio neutro e constante, mas é preenchido com significados nas relações vitais de atuações opostas, e esses significados, por sua vez, mudam de acordo com os diferentes lugares e regiões". Nas relações entre sociedade e trabalho os espaços são construídos socialmente, pelo exercício do poder por determinado grupo ou classe social.

Para Moreira (2002, p. 43):

Cada sociedade se reproduz no espaço por ela criado e que cada espaço reproduz o tipo de sociedade que lhe dá origem, tem-se que, numa sociedade de classes, como a que caracteriza o modo de produção capitalista, o espaço por ela gerado se organiza segundo a estrutura de classes. 
Assim os diversos tipos de trabalho e de demanda são a base para classificação do elemento humano na caracterização de um dado espaço dentro das organizações.

As organizações constituem a forma dominante de instituição de sociedade moderna: representam a manifestação de uma sociedade especializada e interdependente que se caracteriza por um crescente padrão de vida. As organizações permeiam todos os aspectos de vida moderna e envolvem a participação de numerosas pessoas (CHIAVENATO, 2010, p. 93).

As organizações são espaços formados por pessoas, dentro e fora delas, toda organização precisa de pessoas e são as pessoas que determinam o sucesso ou o fracasso de uma organização. Desse modo, os indivíduos que estão dentro ou fora das organizações necessitam delas para viver. Uma das exigências das organizações contemporâneas e competitivas é a excelência do trabalho humano. A existência do ser humano é garantida por meio das relações de trabalho que propiciam a produção das relações socioespaciais.

As organizações têm como função essencial a produção de bens, serviços e ideais, mas também são espaços de conflitos entre os gêneros, uma vez que as pessoas não atuam isoladamente, mas por meio de interação com outras pessoas. Nessas interações humanas as pessoas influenciam-se mutualmente, por meio da participação ou cooperação entre si para alcançar seus objetivos.

Para Santos (2006, p. 86) "dentro das organizações, há uma hierarquia de autoridade e diferenciação de poder que resulta numa divisão de trabalho". A divisão do trabalho pode, também, ser vista como um processo pelo qual os recursos disponíveis se distribuem social e geograficamente.

Essa divisão do trabalho supõe a existência de conflitos. Entre os conflitos existentes nos espaços organizacionais de trabalho, alguns são mais relevantes como o assédio moral e a desigualdade de gêneros.

As relações entre gênero e classe nos permitem constatar que:

No universo do mundo produtivo e reprodutivo, vivenciamos também a efetivação de uma construção social sexuada, onde os homens e as mulheres que trabalham são, desde a família e a escola, diferentemente qualificados e capacitados para o ingresso no mercado de trabalho. E o capitalismo tem sabido apropriar-se desigualmente dessa divisão sexual do trabalho (ANTUNES, 2009, p. 109).

No texto de Higa (2016) diz que "na história da humanidade, o sexo teve grande relevância no papel conferido aos atores sociais, de modo que o acidente do cromossomo X ou Y era capaz de selar a sorte e o destino laboral de uma pessoa por toda a sua existência". A divisão do trabalho por gênero e idade procura justificar a diferenciação entre tipos de trabalho e a criação de papéis específicos a eles vinculados.

Nos espaços organizacionais, existe também a divisão sexual do trabalho que sofreu influxo da concepção patriarcal de divisão de tarefas que trouxe 
vestígios significativos de discriminação, baseado nas diferenças existentes entre homens e mulheres, e justamente essas diferenças que causam os mais atormentados conflitos interpessoais dentro dos espaços organizacionais.

A divisão sexual do trabalho está associada de maneira inextrincável a uma outra configuração que se expressa em termos de relações que associam homens/produção/esfera pública e mulheres/reprodução/espaço privado, conferindo a essas associações, dentro do mesmo princípio hierárquico, uma qualificação da primeira como sendo da ordem da cultura e da segunda como sendo da ordem da natureza (ÁVILA, 2013, p. 234).

A divisão entre a esfera produtiva e reprodutiva fortalece a hierarquia e a desigualdade entre homens e mulheres estabelecendo diferenças entre o sexo.

Para Lima (1997, p. 39), "desde a criação dos tempos o ser humano estabelece diferenças em tudo; em todos os setores onde atua, ele encontra uma maneira de impor distinções e criar critérios de preferências e privilégios de uns em detrimentos dos outros".

Esses critérios no âmbito das relações de trabalho e subordinação se transformam em um abuso de poder hierárquico, significa dizer que se trata da autoridade legítima sobre o subordinado, ou seja, a parte dominante sobre a pessoa. A parte dominante nas relações de trabalho pode destruir o outro por um processo de contínuo e atormentante assédio moral.

Destacar Hirigoyen (2009, p.27) que no "assédio moral não se observa mais uma relação simétrica como no conflito, mas uma relação dominantedominado, na qual aquele que comanda o jogo procura submeter o outro até fazê-lo perder a identidade". Esse jogo perverso pode ser ocasionalmente utilizado nos espaços organizacionais de trabalho, no entanto, ele só se torna destrutivo quando usado com frequência e com a sua repetição no tempo.

Pequenos atos de perversidade são corriqueiros nos espaços organizacionais de trabalho que até podem parecer normais. Começam muitas vezes com uma simples falta de respeito, uma mentira ou uma manipulação e com o tempo elas se transformam progressivamente em condutas perversas ostensivas que têm consequências graves sobre a saúde das vítimas.

\section{Natureza Jurídica do Assédio Moral}

A prática do assédio moral vem se expandindo de diversas formas dentro das organizações de trabalho, causando danos aos envolvidos e provocando discussões na tentativa de elucidar as ações que envolvem e instigam tal prática.

Nesse contexto, é preciso aprofundar os estudos sobre o assunto, uma vez que envolvem outras áreas do conhecimento humano. No entanto, não há previsão legal na legislação trabalhista sobre esse fenômeno patológico das relações de trabalho, exceto em algumas leis esparsas em alguns Estados tipificando a conduta do assédio moral, entretanto, ele já é reconhecido pela doutrina e jurisprudência e tem sido objeto de estudos específicos. 
Para Hirigoyen (2000, p. 17) o assédio moral aduz ser:

Toda e qualquer conduta abusiva, manifestando-se, sobretudo por comportamentos, palavras, atos, gestos, escritos que possam trazer dano à personalidade, à dignidade ou à integridade física ou psíquica de uma pessoa, pondo em perigo seu emprego ou degradando o ambiente de trabalho.

Já Barreto (2000, p. 28) delineia o conceito para a coação moral:

É a exposição dos trabalhadores e trabalhadoras a situações humilhantes e constrangedoras, repetitivas e prolongadas durante a jornada de trabalho e no exercício de suas funções, sendo mais comum em relações hierárquicas e assimétricas, em que predominam condutas negativas, relações desumanas e aéticas de longa duração, de um ou mais chefes dirigida a um ou mais subordinado(s), desestabilizando a relação da vítima com o ambiente de trabalho e a organização, forçando-o a desistir do emprego.

O Código Cível Brasileiro trata do dano moral, que é a consequência do assédio moral, no seu artigo 186, quando diz que "aquele que, por ação ou omissão voluntária, negligência ou imprudência, violar direito e causar dano a outrem, ainda que exclusivamente moral, comete ato ilícito". Nos Estados em que não há legislação específica, ainda é possível pleitear a tutela dos direitos do trabalhador com base no dano moral trabalhista.

Nessa seara, a Consolidação das Leis do Trabalho (CLT) estabelece, no seu artigo 483, as situações de rompimento unilateral de contrato de trabalho quando houver uma falta grave por parte do empregador. Contudo, o assédio moral se constitui numa falta grave por parte da empresa.

$\mathrm{Na}$ Constituição Federal é garantido o meio ambiente saudável ao estabelecer princípios gerais da dignidade da pessoa humana em seu art. $1^{\circ}$, inciso III, como um dos fundamentos da República Federativa do Brasil, "a dignidade da pessoa humana".

Nesse sentido, o artigo $3^{\circ}$, da Constituição Federal, prevê "a construção de uma sociedade livre, justa e solidária".

Ainda o artigo $5^{\circ}$ e incisos $\mathrm{V}$ e X, da Constituição Federal, é taxativa ao afirmar que:

Todos são iguais perante a lei, sem distinção de qualquer natureza, garantindo-se aos brasileiros e aos estrangeiros residentes no país a inviolabilidade do direito à vida, à liberdade, à igualdade, à segurança e à propriedade, nos termos seguintes: [...] $\mathrm{V}$ - é assegurado o direito de resposta, proporcional ao agravo, além da indenização por dano material, moral ou à imagem; [...] X - são invioláveis a intimidade, a vida privada, a honra e a imagem das pessoas, assegurado o direito a indenização pelo dano material ou moral decorrente de sua violação. 


\section{Gênero e o Assédio Moral no Trabalho}

O assédio moral não é um fenômeno recente, pois é observado nas relações humanas desde os primórdios da história, é tão antigo quanto o próprio trabalho. É praticado desde o início da relação laboral. Antes de iniciarmos a falar do tema gênero e assédio moral no trabalho será necessária uma explicação do que é gênero.

Para Silva (2003), o "ser mulher se define num contexto de relações sociais e a identidade feminina é, portanto, permanentemente reelaborada, está em constante movimento".

Joan Scott (1994, p. 13) diz que "gênero é a forma de organizar a sociedade a partir da diferenciação de papéis, de atributos, de valores, deveres e obrigações entre os sexos". Assim, enquanto sexo na visão biológica distingue masculino de feminino, pontua apenas a existência das diferenças biológicas e físicas para a definição de gênero no que diz respeito à visão do homem sobre a mulher, enquanto gênero no sentido estrito classifica os seres humanos pela visão sociocultural. Em se tratando das relações de trabalho prevalece a visão biológica para a divisão de tarefas em uma organização originalmente masculina, construídas socialmente, acreditando-se que em diferentes épocas havia o sexo superior.

Segundo Silva (2013) o domínio dos homens sobre as mulheres desenvolvese, historicamente, pela necessidade de controlar a reprodução e seus vários aspectos e define uma sociedade patriarcal.

A desigualdade entre homens e mulheres tomou feição mais cultural do que biológica, visto que a mulher tem provado, a cada dia, que é tão inteligente quanto o homem e nada deixando a desejar no desempenho das atividades 
intelectuais.

A crescente participação da mão de obra feminina nas organizações não foi suficiente para diminuir a desigualdade entre os gêneros, os conflitos resultantes dessa heterogeneização da força de trabalho têm contribuído para discriminação, que é um componente essencial do assédio moral, dificilmente se vê uma discriminação sem ser acompanhada do assédio moral.

$\mathrm{O}$ assédio moral tem uma direcionalidade e uma intencionalidade, visto que o assediador exerce um poder em relação a alguém que deseja atingir, quer magoá-la, feri-la e fazer o ambiente dessa pessoa um inferno. A pessoa vai sendo isolada, discriminada e sendo transformada em uma pessoa invisível.

Podemos observar tais afirmações no trecho abaixo, retirado de entrevista realizada com uma funcionária quando diz:

Quando foi transferida para trabalhar em uma outra unidade da empresa, tive problemas com colegas de trabalho algum tempo atrás que não aceitavam meu trabalho na unidade que foi designada. Chegou ao ponto de ir para a Justiça, mas foi dado causa ganha a mim e a empresa (Entrevista Trabalhadora, 2017).

Nas palavras de Oliveira (2010, p. 197) "a primeira ideia que surge a respeito do assédio moral aponta para os abusos do poder diretivo do empregador, na figura de um superior hierárquico assediando um subordinado". Esse tipo de agressão é denominado assédio vertical descendente. Também pode ocorrer o assédio vertical ascendente praticado de subordinado para superior ou de pessoas que estão no mesmo nível de hierarquia, como colegas de trabalho, este é chamado assédio moral horizontal.

Nas palavras de Alkimin (2005, p.37):

O assédio moral é uma conduta da natureza humana. Fator social que ocorre no meio social, familiar, estudantil e, mais intensamente, no ambiente de trabalho, abrangendo tanto o setor privado como a administração pública, e, embora na atualidade tenha atraído estudos no campo da Psicologia, Sociologia, Medicina do Trabalho e do Direito, tem origem histórica provocada pela organização do trabalho, tendo em vista a relação domínio entre capital e força de trabalho.

Assim o assédio moral pode ser praticado em qualquer lugar favorecido pelas condições e circunstâncias da própria organização, existem locais de trabalho e pessoas que podem estar mais expostas, isso pode ocorrer tanto no setor público quanto no privado, seja na forma individual por atos de dores com a personalidade, atos obsessivos, ou na forma organizacional resultados de estratégias onde a empresa impõe suas decisões sem considerar a vontade do trabalhador.

O assédio moral tem o objetivo de humilhar, ofender, ridicularizar ou inferiorizar a pessoa, evidencia-se pela violação dos direitos da personalidade vítima do fenômeno, os quais dizem respeito aos atributos que definem e individualizam a pessoa humana.

Nos espaços organizacionais de trabalho as mulheres são as principais 
Gênero e o Assédio Moral nos Espaços Organizacionais de Trabalho: Exclusão

que Causam Feridas

vítimas do assédio moral ou em qualquer outra esfera da vida pública. De acordo com os resultados das entrevistas individuais semiestruturadas, aplicadas com as mulheres trabalhadoras durante os exercícios de suas atividades laborais, relevou que $50 \%$ delas são assediadas por chefes, $33 \%$ por colegas de trabalho e $17 \%$ por clientes. Ressalta que o assediador muitas vezes pela própria insegurança tenta colocar para fora o sujeito impondo disciplina, medo e terror. Um exemplo de como isso acontece pôde ser encontrado no relato de uma entrevistada, que ao descrever uma situação de assédio, disse que:

Certa vez um dos meus chefes solicitou que eu fosse até onde ele trabalhava para que eu passasse o trabalho pra ele, sendo que minha função era totalmente diferente da dele, mas, mesmo assim, me dispus a ajudar. Então quando eu cheguei, ele gritou comigo e disse que eu não fazia nada do que ele pedia e me ameaçou, alegando que eu estava em estágio probatório e que poderia formar sua própria equipe (Entrevista Trabalhadora, 2017).

Sobre essas observações afirma Hirigoyen (2009, p. 99), "as mulheres não somente são mais frequentemente vítimas, como também são assediadas de forma diferente dos homens: as conotações machistas ou sexistas estão muitas vezes presentes". O comportamento machista presente nas organizações contribui para a prática também do assédio sexual que nada mais é do que uma evolução do assédio moral. Nesses dois casos, o agressor trata de humilhar o outro e considerá-lo como um objeto à sua disposição.

Sobre essas conotações machistas, uma entrevistada afirmou:

(...) no ambiente de trabalho somos assediadas de todas as formas, desde a nossa opção de escolha pela nossa roupa, quanto por comentários constrangedores como "ai se eu pego essa aí eu destruo" ou "que bunda, hein, seu marido passa bem" (Entrevista Trabalhadora, 2017).

O assediador na maior parte do tempo não acredita que o seu comportamento seja condenável, uma vez que acredita que faz parte da sua natureza. $\mathrm{E}$ as mulheres que se recusam a certas propostas de um superior ou de colegas passam a ser isoladas, humilhadas ou discriminadas.

Sobre essas afirmações podemos observar no trecho abaixo, retirado de entrevista realizada:

(...) minha gerente dava tarefas além dos meus conhecimentos, cobrava urgência sempre, dava ordens que depois negava ter dado, ameaçava reduzir nosso horário de almoço e sempre exigia que ficássemos além do horário sem pagar hora extra. Também tinha o hábito de gritar conosco (os mais jovens) na frente dos outros, seja colegas de trabalho ou clientes. Há pouco tempo atrás, já como servidora pública, fui isolada em um setor sem computadores ou qualquer outro material de trabalho, nessa sala eu ficava toda a jornada (6 horas) sem receber nenhuma atividade. A porta do setor 
em que eu trabalhava anteriormente foi arrombada durante uma licença por motivo de doença e mesmo sem eu estar presente na data dos fatos fui considerada como suspeita (e a outra encarregada do setor também), desde esse fato fomos convocadas para duas reuniões onde me senti forçada a admitir o envolvimento com o fato, diante de minha negativa e resistência fui ameaçada de ser exonerada. Exigi que a empresa pública acionasse as câmeras de vigilância e me mostrassem o culpado e que se retratassem comigo, inclusive solicitei uma reunião via memorando com os gestores. Desde esse dia a gerente administrativa financeira ficou chateada e passou, em conjunto com o diretor, a me excluir (Entrevista Trabalhadora, 2017).

A discriminação de gênero surge como o pano de fundo para a ocorrência do assédio moral no ambiente de trabalho e em outras esferas públicas. Frequentemente quem mais sofre com a violência no trabalho são as mulheres, considerando que no mercado de trabalho não se fala em igualdade de gênero, sobretudo quando se sobe na hierarquia, diz-se simplesmente que as mulheres não estão aptas a postos de responsabilidades, sendo colocadas à margem da desigualdade ou assediadas unicamente pelo simples fato de serem mulheres.

Para as mulheres o espaço organizacional de trabalho é mais perverso do que para os homens, pois além do controle e da fiscalização, são discriminadas e assediadas.

Destaca que a Organização Internacional do Trabalho (OIT), por meio da Convenção 111, tratou a respeito da discriminação em relação a emprego e profissão, quando definiu discriminação como sendo: "Toda distinção, exclusão ou preferência, com base em raça, cor, sexo, religião, opinião política, nacionalidade ou origem social, que tenha o efeito de anular ou reduzir a igualdade de oportunidade ou de tratamento em emprego ou profissão".

No que tange a eliminação das formas de discriminação contra as mulheres o artigo $1^{\circ}$, da Convenção Eliminação de Todas as Formas de Discriminação contra a Mulher definiu a discriminação sexual como sendo:

Toda distinção, exclusão ou restrição baseada no sexo e que tenha por objeto ou resultado prejudicar ou anular o reconhecimento, gozo ou exercício pela mulher, independentemente de seu estado civil, com base na igualdade do homem e da mulher, dos direitos humanos e liberdades fundamentais nos campos político, econômico, social, cultural e civil ou em qualquer outro campo.

Nas relações de trabalho a discriminação pode transparecer de várias maneiras. E no que diz respeitos às mulheres, são inúmeros os fatores que a discriminação e que não raramente resultam em assédio moral. Vale sublinhar que a discriminação e os assédios contra as mulheres na relação de emprego advêm de um ranço preconceituoso da diferença entre os sexos, visto que a sociedade ainda guarda resquícios históricos da desigualdade contra as mulheres e ideais antigos, o que acaba respigando nas relações de trabalho e gênero. 


\section{Consequência do Assédio Moral}

O assédio moral causa graves danos à saúde de pessoas que se calam diante de tantas perversidades e absurdos cometidos no meio laboral e consiste em um mal avassalador que ocorre usualmente na relação entre chefes e subordinados, podendo ocorrer também nas relações horizontais, ou seja, entre pessoas do mesmo nível hierárquico ou de subordinados para superiores hierárquicos. A característica principal do assédio moral é a exploração do medo dos trabalhadores diante do desemprego por meio de uso de ameaças de demissões.

O assédio nasce como algo inofensivo e propaga-se insidiosamente. Em um primeiro momento, as pessoas envolvidas não querem mostrar-se ofendidas e levam na brincadeira desavenças e maustratos. Em seguida esses ataques vão se multiplicando e a vítima é seguidamente acuada, posta em situação de inferioridade, submetida a manobras hostis e degradantes durante um período maior (HIRIGOYEN, 2010, p. 67)

Observa-se que assédio moral caracteriza-se antes de tudo pela repetição de atitudes, palavras, comportamentos, que, tomados separadamente, podem parecer inofensivos, mas quando repetidos e sistematizados tornam-se destruidores. $\mathrm{O}$ assédio moral de certa forma provoca a degradação do meio ambiente de trabalho e consequentemente a saúde dos trabalhadores. Vale destacar que não se trata de mero estresse, desentendimentos ou conflitos individuais pontuais característicos do convívio humano, trata-se de conduta deliberada, intencional, com o objetivo de atacar a vítima na sua autoestima com atitudes desgastantes e humilhantes. Esses tipos de condutas podem ser evidenciados na fala de uma das entrevistadas, que afirma:

(...) penso que se trata de uma pessoa que sente prazer em subjugar os demais, uma espécie de certeza da impunidade, pois essa conduta só acontece com os funcionários mais jovens e recém-contratados (...) penso que se trata de uma rixa pessoal, pois como não cedi às ameaças e não fiz a vontade dos gestores sofri e ainda sofro as represálias (Entrevista Trabalhadora, 2017).

Entre as consequências do assédio moral predominam as depressões e as angústias, além dos desgastes psicológicos e emocionais decorrentes das relações de poder e interpessoais no ambiente ocupacional.

Tais consequências sobre o trabalhador podem ser evidenciadas na fala de uma das entrevistadas, que afirma:

Uma vez fui convocada para participar de uma reunião de diretores na empresa e um superior me expôs diante de um comitê administrativo me fazendo perguntas que ele já sabia que eu não iria saber responder, para me humilhar e provar que eu não era capaz 
O assédio moral, segundo as observações de Inácio (2012, p.54), “afeta negativamente o bem-estar do trabalhador, uma vez que reflete não apenas em sua eficiência, mas também nos outros trabalhadores, pois instala a negligência, o absenteísmo e o aumento dos pedidos de licenças médicas". Entre outros, o assédio moral pode deixar sequelas marcantes que podem evoluir do estresse pós-traumático para uma mudança na personalidade da pessoa. As lembranças das cenas de humilhação vividas se impõem sobre a pessoa assediada, que não consegue se livrar delas, as imagens das agressões funcionam como flashbacks dolorosos.

Entre os acontecimentos na vida com o assédio moral servem para ferir, desgastar, minar as pessoas, fazendo-as perder toda a ilusão e a esperança. As agressões sofridas no local de trabalho causam feridas que podem ser reativadas em outros eventos da história íntima das pessoas. Em alguns momentos da vida a pessoa torna se fragilizada, irritada, sensível ou muitas vezes agressiva, capaz de gerar inúmeros conflitos no ambiente de trabalho, inviabilizando o convívio com os demais colegas. Podemos observar tais afirmações no trecho abaixo, retirado de entrevista realizada com uma funcionária pública que, após um longo período de afastamento sem ter sido exonerada, foi obrigada a retornar. Segundo a entrevistada:

Estou bem porque hoje trabalho em um local onde me sinto valorizada, mas caso eu tivesse continuado nos dois ambientes onde sofria assédio certamente haveria muita sequela mental e emocional. Afirmo isso porque quando fui convocada a retornar ao segundo emprego (de onde ainda não pedi exoneração) me senti muito triste e temerosa pelo que poderia acontecer. Tinha a certeza de que seria excluida novamente (Entrevista Trabalhadora, 2017).

Percebe-se que o assédio moral no ambiente de trabalho é, sem dúvida, um sofrimento demasiadamente desnecessário para aqueles que sofrem com este tipo de agressão que pode ir além dos ataques físicos ou psicológicos.

As consequências do assédio moral são devastadoras, pois além dos danos físicos e psicológicos podem acarretar a desestruturação da identidade e influenciar no temperamento da pessoa por muito tempo. A humilhação repetitiva e de longa duração acaba interferindo diretamente na vida do empregado, comprometendo sua identidade, dignidade e relações sociais e afetivas.

Nesse diapasão analisa Hirigoyen (2009, p.175), “quando somos vítimas de uma agressão contra a qual não temos meios psíquicos de lutar, pode ocorrer uma acentuação de traços de personalidade anteriores ou surgir distúrbios psiquiátricos". Nesse diapasão, o assédio moral pode ocasionar em alguns um estado depressivo que pode gerar alienação do indivíduo e uma total solidão. Enquanto outros podem passar a agir de forma agressiva e com acessos de ira. Vale destacar que o assédio moral é muito mais do que um estresse, visto que o estresse só torna destruidor pelo excesso, já o assédio é destruidor por si só. 


\section{Considerações Finais}

Este artigo teve por objetivo analisar os diversos fatores que contribuem para a propagação do assédio moral de gênero nos espaços organizacionais de trabalho, considerando as representações sociais construídas em torno do gênero. Observou-se que a maior parte do assédio acontece na forma vertical descendente, ou seja, na figura de um superior hierárquico nas diversas áreas e setores de trabalho. A pesquisa também revelou um número expressivo de assédio moral praticado por pessoas que estão no mesmo nível de hierarquia, como colegas de trabalho, o chamado assédio moral horizontal.

As formas de assédio moral mais praticados nas organizações de trabalho estudadas são provocados pela falta de comunicação; estímulo da rivalidade nos ambientes; uso da manipulação de pessoas, para originar uma desestruturação emocional; diminuição do número de cargos; e crescentes exigências de produtividade

Os resultados encontrados apontaram que as mulheres são mais vulneráveis e frequentemente mais assediadas no ambiente de trabalho que os homens. A pesquisa apresentada neste artigo permite crer que a existência das diferenças físicas, biológicas e sociais entre mulheres e homens contribui para promover uma desigualdade nos espaços organizacionais de trabalho e assédio moral de gênero.

Estas desigualdades são fatos destacáveis para o desencadeamento do assédio moral vivenciado pelas trabalhadoras. Notou-se, portanto, que assédio moral sempre fez parte do cotidiano de homens e mulheres no ambiente de trabalho, afetando diretamente a integridade física e mental dos trabalhadores. Entretanto, tais ocorrências apresentam-se de forma mais perversa e discriminatória em relação às mulheres, que se deparam com diferentes situações de constrangimento, reflexos da desigualdade de gênero.

Percebe-se que o mito da igualdade está presente apenas nos discursos culturais que denotam o tratamento diferenciado à mulher, quando na realidade ela continua sendo discriminada e assediada pelo simples fato de ser mulher. $\mathrm{O}$ fato das mulheres serem as principais vítimas do assédio está associado à cultura do patriarcado, que coloca a mulher em um patamar de submissão em relação ao homem. Isso pode ser percebido em algumas frases preconceituosas e discriminatórias atribuídas a características físicas e biológicas da mulher.

Neste sentido, as conclusões deste artigo poderão contribuir para ampliar o debate sobre a problemática do assédio moral de gênero nas organizações, que é um processo lento e silencioso, que pode comprometer a saúde física e psicológica da vítima e que precisa ser denunciado e combatido.

\section{Referências}

ALKIMIN, Maria Aparecida. Assédio Moral na Relação de Emprego. Curitiba: Juruá, 2005.

ANTUNES, Ricardo L. C. Os Sentidos do Trabalho: ensaio sobre a afirmação e a negação do trabalho. $2^{a}$ ed., 10. reimpr. rev. e ampl. - São Paulo, SP: Boitempo, 2009. 
Gênero e o Assédio Moral nos Espaços Organizacionais de Trabalho: Exclusão

que Causam Feridas

ÁVILA, Maria Betânia de Melo. A dinâmica do trabalho produtivo: uma contradição viva no cotidiano das mulheres. In: Mulheres brasileiras e gênero nos espaços públicos e privado. São Paulo: Editora Fundação Perseu Abramo: Edições Sesc SP, 2013.

BARRETO, Margarida Maria Silveira. Uma jornada de humilhações. Dissertação (Mestrado em Psicologia Social) - PUC, São Paulo, 2000.

BOLLNOW, Otto Friedrich. O homem e o espaço. Tradução Aluísio Leone Schmid - Curitiba: Editora UFPR, 2008.

BRASIL. Decreto-lei $n^{0}$ 5.452, de $1^{\circ}$ de maio de 1943. Disponível em: $<$ http://www.planalto.gov.br/ccivil_03/decreto-lei/Del5452.htm> Acesso em 2 de março de 2017.

BRASIL. Constituição (1988). Constituição da República Federativa do Brasil.

Disponível em: $<$ http://www.planalto.gov.br/ccivil_03/Constituicao/Constituicao.htm $>$ Ace sso em 2 de março de 2017.

BRASIL. Lei $\mathrm{n}^{0} \mathbf{1 0 . 4 0 6}$, de 10 de janeiro de 2002. Disponível em: $<$ http://www.planalto.gov.br/ccivil_03/leis/2002/L10406.htm> Acesso em 2 de março de 2017.

BRASIL. Decreto-lei $n^{0}$ 4.377, de 13 de setembro de 2002. Disponível em: $<$ http://www.planalto.gov.br/ccivil_03/decreto/2002/d4377.htm> Acesso em 2 de março de 2017.

CHIAVENATO, Idalberto. Iniciação à teoria das organizações. Barueri, SP: Manoele, 2010.

HIGA, Flávio da Costa. Assédio sexual no trabalho e discriminação de gênero: duas faces da mesma moeda? Revista Direito GV, v. 12, n. 2, p. 484 - 515, 2016.

HIRATA, Helena; KERGOAT, Daniele. Divisão sexual do trabalho profissional e doméstico: Brasil, França, Japão. Mercado de trabalho e gênero-comparações internacionais. Rio de Janeiro: Editora Fundação Getúlio Vargas, 2008.

HIRIGOYEN, Marie-France. Mal-estar no trabalho: refinando o assédio moral. Tradução Rejane Janowitzer. $4^{\mathrm{a}}$ ed. Rio de Janeiro: Bertrand Brasil, 2009.

HIRIGOYEN, Marie-France. Assédio moral: a violência perversa no cotidiano. Tradução Maria Helena Kuhner. 12a ed. Rio de Janeiro: Bertrand Brasil, 2010. 
Gênero e o Assédio Moral nos Espaços Organizacionais de Trabalho: Exclusão

que Causam Feridas

HIRIGOYEN, Marie-France. Assédio Moral: a violência perversa do cotidiano. Rio de Janeiro: Bertrand Brasil, 2000.

INACIO, Aparecido. Assédio moral no mundo do trabalho: doutrina, jurisprudência e casos concretos. São Paulo, SP: Ideias \& Letras, 2012.

LIMA, Francisco Gérson Marques. Igualdade de tratamento nas relações de trabalho. $1^{\text {a }}$ ed. São Paulo: Malheiros Editores, 1997.

MOREIRA, Emilia. O espaço enquanto produto do trabalho: uma contribuição ao ensino de geografia. Cadernos do Logepa, v. 1, n. 2, p. 33 - 46, 2002.

OLIVEIRA, Sebastião Geraldo de. Proteção Jurídica do Trabalhador. $5^{\mathrm{a}}$ ed. São Paulo: LTr, 2010.

SCOTT, Joan. Gênero: uma categoria útil de análise histórica. Educação e Realidade, v. 16, n. 2, p. $71-99,1990$.

SILVA, Joseli Maria. Um ensaio sobre as potencialidades do uso do conceito de gênero na análise geográfica. Revista de História Regional, v. 8, n. 1, p. 31 - 45, 2003.

SILVA, Susana Maria Veleda da. A contribuição dos estudos de gênero para a compreensão da geografia do trabalho: uma pauta para discussão. Revista Latino-americana de Geografia e Gênero, v. 4, n. 2, p. 106 - 117, 2013.

SANTOS, Milton. A Natureza do Espaço: Técnica e Tempo, Razão e Emoção. $-4^{\mathrm{a}}$ ed. 2. reimpr. - São Paulo: Editorada Universidade de São Paulo, 2006. 